\title{
Why E-Commerce Remains Unsuccessful in Pakistan?
}

\author{
Shamaila Hasan Khan \\ Mr. Zeeshan Arshad*
}

\begin{abstract}
This research was undertaken to uncover issues that affect success of E-Commerce in Pakistan. More focus was on socio-cultural aspect of the issues and influences but alongside technological and political issues were also discussed. This issue was addressed by selecting six traditional E-Commerce Models which were discussed in interviews conducted with ten people who have been involved in the implementation of E-Commerce in Pakistan. The interviews were open-ended, starting with a general discussion on the E-Commerce environment of Pakistan and then six models were discussed one by one. The respondents gave their perspective on the pros and cons of each model and also the reasons why $E$ Commerce has not gained as much popularity as it has in the rest of the world. The research was exploratory in nature with the aim of collecting information of the perspectives of the seller side of market. Due to time limitation, respondents were from Karachi only and were selected though convenience. It is recommended that the research should be replicated for other major cities of Pakistan to gain a better understanding of the issues.
\end{abstract}

Keywords: E-Commerce, E-Commerce in Pakistan, online retailing, virtual communities, online advertisement, E-Commerce in developing countries, internet, computer, online business.

\section{1 - Introduction}

The popularity of E-Commerce (or Electronic Commerce) is increasing day by day. As Elaine Rubin, Co-founder and Chairman of shop.org says recalling the past that people in their own company did not believe that the customers will actually take out their credit cards and buy through the computer (National Retail Federation, 2004). But they did and the users came in large numbers. Within 15 years, E-Commerce became immensely popular. People see computer a convenient way to do just about everything, from socializing to shopping to using it to extract information and it can be attributed to ECommerce to a large extent.

The definition of E-Commerce is somewhat fluid, some people use E-Commerce and E-Business interchangeably. This research used the following definition:

"...the use of electronic transmission mediums (telecommunications) to engage in the exchange, including buying and selling, of products and services requiring transportation, either physically or digitally, from location to location." (Greenstein and Vasarhelyi, 2002) 
Research has shown that the fast growing popularity of E-commerce has been attributed to its numerous advantages. It provides access to wider range of customers, in particular, small and medium sized business as they can sell globally without a costly investment in warehouses, retail shops, etc. It also cuts down cost on conventional intermediaries and enables a direct connection between the manufacturer and customers (Sajid, 2003). Another lucrative aspect of E-commerce is that it takes the business out of time limitations such that your business is "open" 24/7 (Reynolds, 2000).

Since small and medium sized businesses form a major part of the developing economies, Ecommerce has great potential of growth at both state and individual level. Pakistan's economy is no different. Pakistani government realized this opportunity and started Information Technology (IT) and Ecommerce initiative as early as 2000 , where banks were expected to lead the way (The Economist Intelligence Unit, 2006) but it faced a number of hindrances in its successful implementation and currently rank as the second lowest adopter (40\%) of E-commerce followed by Philippines (45\%) (Neilson, 2008).

However, statistics show that internet users have been growing at an amazing rate. Pakistan $(18.5 \%$ of people using Internet and $2.6 \%$ of the people of Asia) ranks $8^{\text {th }}$ in the top ten countries of Asia, with regard to usage of Internet. It witnessed a remarkable growth of $13,716.3 \%(13,900$ to $18,500,000)$ during the period 2000-2009 (Internet World Stats, 2009) and is expected to have a three digit growth in next couple of years till around 22 million by the year 2013 (The ARY News, 2009). It has expanded from 29 cities in 2000 to 2,339 cities by June 2006 (The Economist Intelligence Unit 2006). 4.3 million users have been estimated to have a broadband connection (The ARY News, 2009).

The question then arises, why is E-Commerce still not popular despite such an astonishing growth in Internet usage?

\subsection{Research Problem}

To answer this question an exploratory research was undertaken to investigate the issues and influences in successful implementation of E-commerce in Pakistan. This issue was addressed in two phases. The first phase included an assessment of traditional E-commerce models and why are they not applicable to our society. In the second phase, a model is suggested that is tailored to meet the identified issues, keeping in mind the policies, infrastructure and socio-cultural make-up of Pakistan.

\section{2 - Objectives of the Study}

The study aimed to achieve the following objectives:

- To gather and assess the traditional world models of E-commerce used in the developed countries.

- To find out why those models are not applicable in Pakistan.

- To find out issues unique to the socio-cultural make-up of Pakistan.

\section{3 - Research Methodology}

These objectives were achieved through a qualitative analysis of the data gathered through primary and secondary sources.

Primary data was collected through interviews of 10 people selected on the basis of convenience and who were aware of the traits and different aspects of Pakistani consumers being involved in implementing a website. The interview was based on the gathered information from secondary sources of the traditional E-commerce models. Convenience sampling was selected due to difficulty in finding a complete list of E-Commerce websites or software houses involved in implementation of such sites. 
Further, no response was achieved after contacting a few. The secondary data was collected through books, journals, articles and internet sources.

Since the main objective of this study was to gather information, the interviews were open ended and only probe questions were asked to clarify or elaborate on a subject. Each interview lasted for about an hour. First, the interviewees were asked to comment on Pakistan's current situation regarding ECommerce in general. Then 3 Models (namely Online Retailing, Brokerage and Virtual Community) were given one by one and discussed in detail. After that, three more models were discussed briefly (namely Advertising, Auction and Content Provider). At the end of the interview, a summary of the interview was read to the interviewee to make sure that they had agreed with what was recorded.

Due to limitation of time and vastness of the subject, the current research was undertaken as an exploratory research and henceforth, some of the issues identified should be analyzed in-depth before going on to the next stage as mentioned in the problem statement.

For this purpose, existing literature of similar researches carried on other developing nations was surveyed. Also, previous studies carried out in Pakistan of similar nature were used to identify the issues and if they still have an influence now.

\section{2 - E-Commerce in Developing Countries: An Overview}

A number of researches carried out in developing countries point to more varied issues than just infrastructure or security problems which have been traditionally accused for unpopularity of ECommerce (Zwass, 1999; Wolcott et al., 2001; Travica, 2002). Trust (Efendioglu et al. 2004; Bajaj and Leonard, 2004) was identified as a key factor. Efendioglu et al. (2004) in their study on China identified several factors. First was infrastructure and e-support which included lack of credit cards and convenient payment means, poor distribution logistics, lack of specialized trustworthy online merchants of reasonable size, imperfect legal system and lack of high speed connections. The users of ecommerce also identified the following problems: lack of internet security, lack of feel-and-touch associated with online purchases, problems in returning goods and selection. This, along with lack of trust and belief that "debt is not good" formed the sociological and cultural impediments against ECommerce.

Bajaj and Leonard (2004) proposed a "CPT" (Culture-Policy-Technology) framework. Cultural aspect is divided further into trust, level of corruption and pattern of communication. Policy includes 1) policies related to general trade and economy 2 ) policies targeted specifically to enabling internet usage and ecommerce. Technology includes 1) the level of hard wired telecommunications infrastructure that exists in an economy 2) the level of computer engineering expertise in an economy 3) the level of wireless infrastructure within an economy.

Researches carried out in Pakistan came up with similar results. They showed that Pakistan is also confronted by problems like inadequate infrastructure - frequent power failures and insufficient phone lines and lack of security for online transactions (Sajid, 2003; The Economist Intelligence Unit, 2006; Petrony, 2009). Previously, low number of internet users were also a problem, but as we saw that problem is no more a major hindrance and would cease to be so in future. Mistrust, low literacy rate, access to new technology, government policies, unavailability of proper infrastructure, monopoly of PTCL, high bandwidth rates and limited internet users are obstacles in the successful implementation of E-Commerce. Tunyo (2008) adds to the above list and mentions another very important factor which is traditionalist nature of Pakistani society. He elaborates it by mentioning two aspects of it. First, that customer develops relationship and long term association with the vendors which are maintained over the years. Second, that mostly business is conducted through small local entrepreneurs who are less educated and least eager to embrace new technology. Another point mentioned by the same author is poor distribution/transportation channels. The Pakistan Postal service is inefficient and unreliable and has become infamous over the years. On the other hand, private courier services are expensive. 
But is the picture as gloomy as it seems? The next section talks about the achievements of Pakistan in terms of technological advancements.

\section{3 - Technological Advances in Pakistan}

Pakistan is one of the few countries with an advance infrastructure amongst the developing countries. In the past few years, it has transformed the previous analogue low speed communication network into a high speed broadband infrastructure (Bajwa, 2009). But it still lacks when it comes to E-commerce infrastructure and electronic payment gateways. However, there have been recent developments in this regard.

In Pakistan, there is a growing trend of online banking and usage of cards (including debit, credit, ATM) (Khan, 2009). Moreover, UBL has introduced Visa Debit cards, known as UBL WIZ card, which are specially geared towards online shopping for people who do not like using credit cards (Attaa, 2009). This card is serving purpose in a viable and affordable way for paying online, particularly since Pakistan does not have PayPal (Pro Pakistani, 2009). Since this research was conducted, there have been talks about further advancements with regard to PayPal coming to Pakistan (Aamir Atta, 2010).

Besides this, Raseen Technologies, a part of Dhabi group of U.A.E has introduced an E-Commerce Gateway. This is expected to resolve the missing infrastructure for online business in Pakistan (Attaa, 2009 and Khan, 2009). However, this is only offered to Bank Alfalah Ltd. customers. It provides a 3DSecure based chargeback protection for merchants and they can sell their products and services easily. Consumers can also request their banks for 3DSecure PIN to protect their cards from fraudulent use (Khan, 2009). However, Bajwa (2009) thinks that this cannot replace PayPal which is a more popular and widely preferred payment method, especially for using internationally. He argues that this could empower the user through a low-cost solution and develop a culture but could not assist in increasing E-Commerce in Pakistan.

As we can see a lot of development is happening on the technological end but is equal importance given to the socio-cultural aspects in particular? Are these technological advancements improving the E-Commerce environment? Is government fulfilling its role in the implementation? Can the ECommerce models used in developed countries be used in Pakistan as well? Six models of ECommerce were selected for research and with these questions, interviews were conducted. Following section summarizes the findings.

\section{E-Commerce: A Pakistani Perspective}

Due to absence of any recent research on E-Commerce in Pakistan, an exploratory research was conducted to identify as many issues as possible in order to further investigate and scrutinize them and finally come up with a solution for them. The focus was mainly on "culture" aspect of the CPT framework (Bajaj and Leonard 2004). For this people involved in the implementation of E-commerce for well-known organizations were interviewed. They were assured anonymity so that they could freely discuss the issues they have come across. The issues identified were then classified as 'general issues' which were common for all models of E-Commerce and those which were specific to a certain model. They are outlined below.

Kurina (2006) compares the model of stages of e-business growth given by McKay and Marshall 2004 and the model of E-Commerce development by Le and Koh (2002) and found both of them consistent. She uses it to evaluate the stage a country stands on in the development of E-Commerce (Fig 1). The findings of the research pointed out that Pakistan was on the "Interactive Online" stage where businesses have an online presence along with modes to get customer feedback and comments and sometimes maintain their profiles as well. 


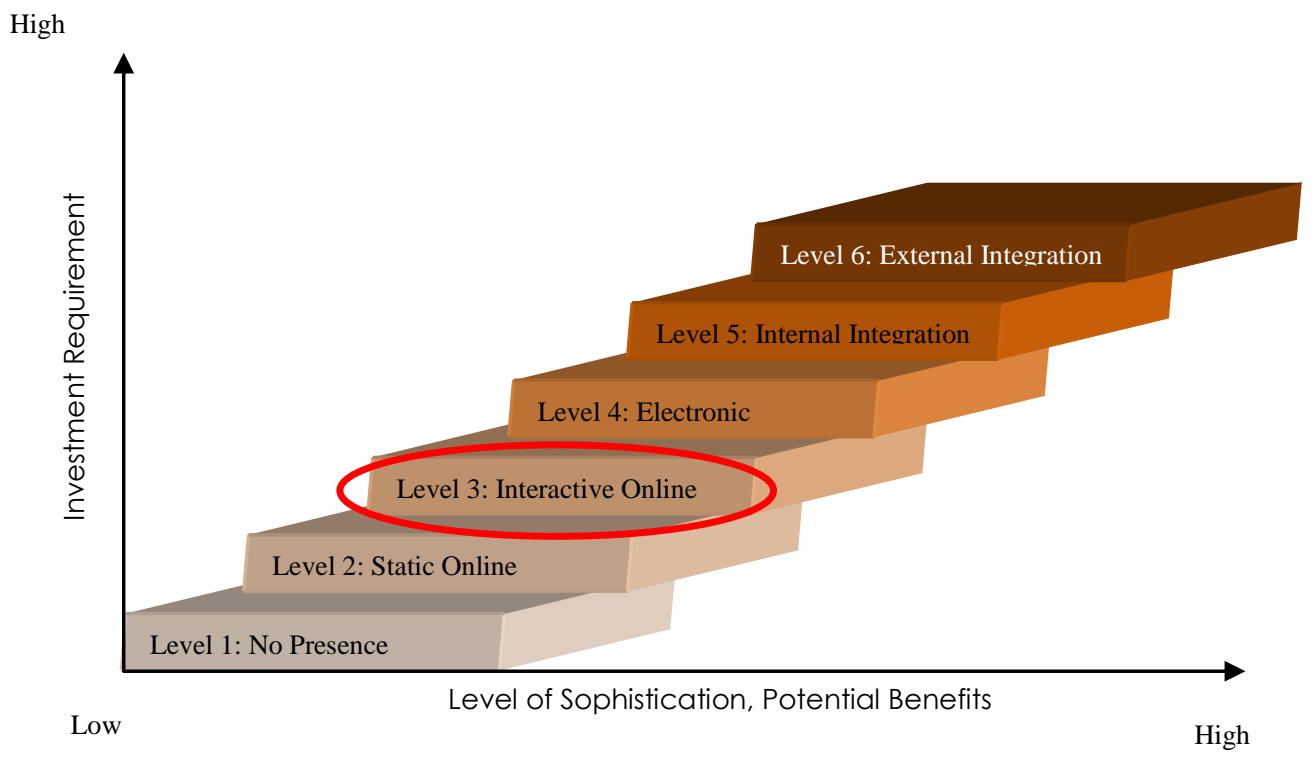

Fig 1: McKay and Marshall (2004) E-Business Stages of Growth

All the respondents were of the opinion that the entire Pakistan should not be focused when talking about making E-Commerce successful. Since it was at such an infancy stage, it should be started by focusing those people who already have internet connections, are computer literate and have means to make purchases over the internet. Some said the problem lies with the demand of E-Commerce. If there is a sufficient demand for E-Commerce from the consumer side, infrastructure and online presence of the businesses will fall into place itself. This observation is opposite of what happened in USA, a developed nation, in its initiation of E-Commerce. The organizations did not see any profit in it but they knew it was the future and they had to keep up with it and hence they became the pioneers (National Retail Federation, 2004).

In countries where shopping was seen as a recreational activity, E-Commerce adoption was difficult (Boerhanoeddin, 2000; Kurina, 2006). The research showed that this was one of the influences for Pakistan. As it was noticed, due to a large number of households with the earning responsibility resting with male members and having maids/servants and drivers to share the household work, shopping is seen as a fun and socializing activity.

E-Commerce is especially good for entrepreneurship as it requires lesser amount of initial investment than brick and mortar business. But it was seen that Pakistani culture is such that it does not encourage entrepreneurship.

Low literacy rate was seen as an impediment in E-Commerce (lqbal, 2008). However, the findings pointed out that it was more important to target people having internet connection and literacy as well. Once it becomes popular there, then measures should be taken to find ways to spread it throughout Pakistan. However, another aspect of literacy which did matter was computer literacy. Many people have a fear of unknown when it comes to technology and that is a main problem.

Lastly, respondents were of the opinion that Pakistan seems to be really low on "trust". Buyers don't trust sellers and vice versa. Credit card misuse, overpricing and selling substandard goods and misinformation from the buyers' side come under the category of trust problems. This contrasts with the fact that "trust" has been identified as a main key characteristic in the success of E-Commerce (Efendioglu et al. 2004; Bajaj and Leonard, 2004; Iqbal 2008). 


\section{Online Retailing}

The interviewees pointed out that most of the online retailing is being done through click and mortar model in Pakistan. In a country like Pakistan, where the customer service is very low, Internet presence may help businesses to increase and improve on it. While having a brick and mortar presence can solve several trust issues and can especially be a convenient way for loyal customers and further, building loyalty. However, having a virtual business is still not a very attractive solution in Pakistan.

Word of mouth and reviews hold an important place in Pakistani consumers' buying behavior. In spite of that, there is no central place to tackle this issue. The blogging community is not very active in this aspect too. Most of the forums are run by expatriates. Also a mishap experienced by one person spreads quickly and affects consumer confidence. This is a very critical hindrance that should be tackled by businesses.

Due to this, several benefits that have always been a hallmark of E-Commerce cannot be achieved fully. One of them is cost reduction (Wen et al. 2001) but as one of the respondents pointed out, it was still a very useful tool to expand the business and partner with different organizations for 'intelligent marketing'.

From the business side, setting up an E-Commerce site is extremely expensive due to administration costs, hosting, merchant accounts, etc. Therefore, a few organizations that are using E-Commerce are known and established brands which have a market outside Pakistan as well (e.g.: English Boot House, JafferJees).

Pakistan's history has a number of scams and frauds that have gone unpunished and not reimbursed by the government; this was a general perception of the respondents. This lack of regulation has lessened the consumer confidence in the governmental policies. Unstable economic conditions, changing regulations with each government change, government initiative, adequate regulatory framework including taxation and tariffs from E-Commerce and public policy are important for ECommerce success. The findings pointed out that they are not being addressed in Pakistan. However, this issue needs to be further investigated.

\section{Brokerage Model}

The findings showed that due to low number of buyers and sellers, the current E-Commerce situation does not provide a lucrative platform to implement the brokerage model. Even though the numbers of internet users are increasing, they are not willing to make transactions online due to afore discussed reasons.

The research also pointed out that it was a higher form of E-Commerce, the reasons can be established by aforementioned general limitations. Unless basic infrastructure and trust issues are solved in Pakistan and people become comfortable with doing commerce online, it is very unlikely that the brokerage model can be implemented in B2C E-Commerce.

\section{Virtual Community Model}

The Community models are becoming very popular over the internet. In Pakistan's scenario, people usually join communities related to their field of expertise, to socialize or play online games. However, communities like Facebook provide all three for no payment. In the same way Orkut, $\mathrm{Hi5}$, etc provides a place to socialize for free and also provide an option to build and join communities based on common interests.

The respondents said that with free options already on the horizon it is very unlikely that people in Pakistan would pay a subscription fee to join a community. Advertising as will be discussed is not a very viable option for Pakistan's current scenario of E-Commerce. High start up costs further deters 
people from venturing and exploring these models. Apna Karachi is one example which has grown unpopular in recent years.

Another major challenge is to build consumer confidence and a known brand name. Only then will the consumers know that their information is safe.

Some interviewees said that linking a community with a product or service is also a very viable option, where the above mentioned problem can be somewhat solved. For example Linkedin enables people to join communities and create social networks and also help companies to advertise their jobs. However, with established and known options people are very skeptical to use a Pakistani website providing the same services due to a general mistrust regarding the regulation, security, and narrow scope of the purpose. As seen in the findings, it stems from educational and maturity level of the consumers.

The findings pointed out that if there can be an opportunity for this model in Pakistan, it can be in gaming industry. Gamers tend to spend exaggerated amounts of money on gaming. The gaming industry unlike developed countries is mainly dominated by teens. Providing teens with a means for spending online is critical for its success.

\section{Others}

Advertising E-Commerce model has opened up a whole new horizon of opportunities. However, its assumption at the bottom is high internet traffic. Since already discussed, even though internet usage is increasing, most of the users are visiting international sites. Traffic still needs to increase with the help of organizations, bloggers and communities and only then can it be successful. Therefore, generating revenue through advertisements in the current socio-cultural and technological environment is difficult in Pakistan's case.

Auction Model was seen to have similar drawbacks which included low traffic, mistrust and frauds. Like brokerage, it is a higher form of E-Commerce and cannot be implemented till the rest of the issues are solved. Content provider's biggest hindrance in implementation is piracy issues. When people can get content for free or at very low rates, they would not pay for the content or subscription to download.

The issues are summarized in Table 1. 
Table-1

\begin{tabular}{|c|c|}
\hline Category & Issues \\
\hline General Issues & $\begin{array}{l}\text { - Lack of Demand } \\
\text { - } \text { Mistrust } \\
\text { - Lack of Awareness of Technology } \\
\text { - } \text { Focusing entire Pakistan }\end{array}$ \\
\hline Online Retail Model & $\begin{array}{l}\text { - Expatriates and Click and Mortar are the most } \\
\text { popular sub-models } \\
\text { - Infrastructure } \\
\text { - Lack of Regulation } \\
\text { - Traditionalist nature of Pakistanis }\end{array}$ \\
\hline Brokerage Model & - Higher form of E-Commerce \\
\hline Virtual Community Model & $\begin{array}{l}\text { - Lack of Willingness to Pay } \\
\text { - } \text { Advertising } \\
\text { - } \text { Cost } \\
\text { - Educational and Maturity Level }\end{array}$ \\
\hline Others & $\begin{array}{l}\text { - Secondary to the models mentioned above } \\
\text { - Piracy Issue }\end{array}$ \\
\hline
\end{tabular}

Table 1: Summary of the Issues faced in the Success of E-Commerce in Pakistan

Several Issues identified were unique to the socio-cultural makeup of Pakistan. The first was the influence of joint family systems, responsibility of supporting a family. According to the research this made it convenient to derive a steady income rather than going for risk-taking entrepreneurship. Setting up businesses is therefore, limited to certain families and communities which have networks and means to help set up new ventures or those who could not find a job and it was better for them to take risk than have nothing.

Responsibility of earning resting with the male members of the house was another influence that was identified combined with having maids, servants and/or drivers. This makes shopping a fun experience rather than a chore. Shopping on the internet to avoid crowds and doing it at the convenience of home becomes useless (National Retail Federation 2004).

A third one is sky rocketing prices and increasing inflation. This has lowered the buying capacity of most of the people and made luxury items unaffordable.

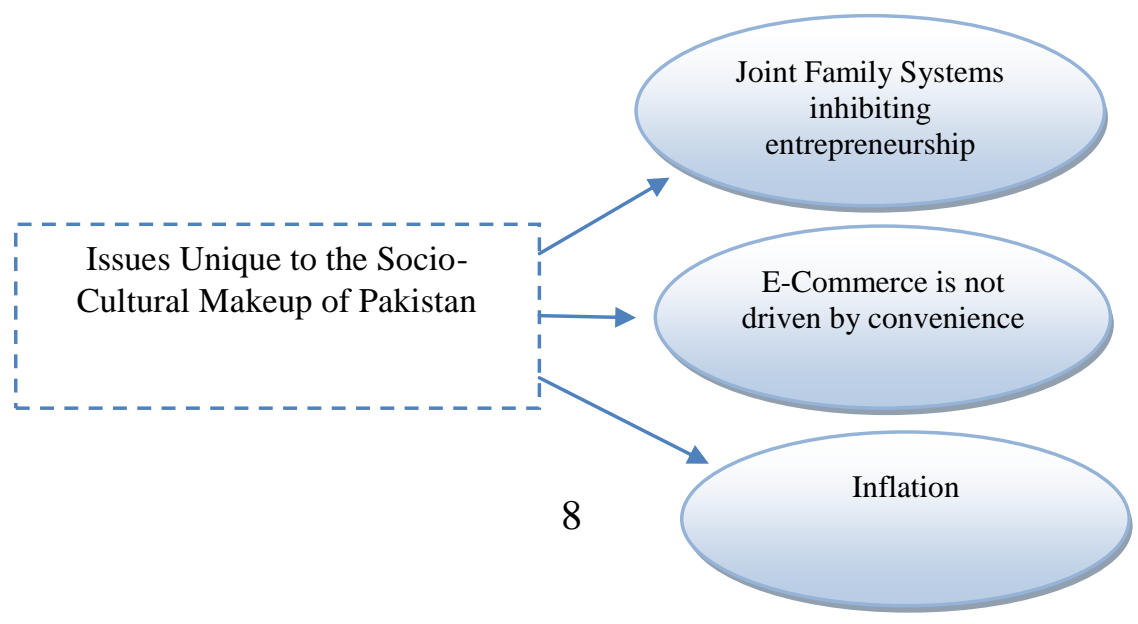


Fig 2: Issues Unique to the Socio-Cultural Makeup of Pakistan

These are three issues that the research uncovered as being unique to Pakistan's market.

\section{Conclusion}

The research findings show that Pakistani market is still not mature enough for E-Commerce due to the numerous problems it faces and lack of demand for E-Commerce. The lack of demand could, however, stem from the socio-cultural issues.

The research pointed out to a number of issues and influences in the successful implementation of ECommerce. Since the research was of exploratory nature and the aim was to gather as much data as possible regarding the topic, without going into the details of each issue. Therefore, it is recommended that further research should be conducted building upon this one to further clarify and study the issues and influences.

The research also pointed out to three influences unique to Pakistan and was an important finding. It should be further researched to see how much impact it has on the implementation of E-Commerce in Pakistan.

Lastly, apart from the socio-cultural issues which were the focus of the research, some technological and political issues were also found during the study.

\section{Recommendations}

Following are some recommendations that were collected during the research, followed by recommendations from researcher.

During the interview the respondents gave several recommendations. They were of the opinion that ECommerce should focus on people with a computer and an internet connection and specifically, the generation that is already comfortable with internet and computers. Besides this E-Commerce should not only be seen as a source of high revenue, rather a necessity to keep up with the global trend. A good way to achieve this is by building partnerships between organizations and to make E-Commerce popular. This is already happening in offline businesses in many ways. E-Commerce needs to do the same for building trust and credibility and introducing new brands and should try to create associations.

This can be done by allowing some products, discounts or deals to their members of their "online club". Credibility should be built through reviews done by prestigious universities, famous magazines and credible people whom the consumers trust. It is more likely that people will buy brands they already trust without physically inspecting them. Therefore, they should be encouraged to buy them online.

The conclusion of the research brought forth issues for which following are recommended by the researcher. However since it was an exploratory research, several factors need to be further researched before solutions can be recommended.

The issue central to the success of E-Commerce is customer service. The organizations need to improve their customer service to secure their trust and credibility. Universities and educational institutions should take initiative to make their students and faculty comfortable in using E-Commerce since those are the people who would be building the future of commerce. This can be done by offering 
means to pay online, create partnerships with book retailers, to purchase books online on discount, etc. Most of them already maintain websites to provide updated information and can be easily extended to include this aspect too. The issues regarding the implementation should however be further researched.

The focus of this research was the socio-cultural traits of Pakistani people which influence the implementation of E-Commerce. For this purpose, CPT (culture-policy-technology) model was selected. However, due to time limitation, policy and cultural aspects could not be studied in-depth.

Due to the vastness of the subject and time limitation, the study was restricted to interviewing people from Karachi. This study should be replicated in other major cities as well. Another aspect which requires further research is implementation of E-Commerce at University level. A study should be undertaken to check the feasibility of this recommendation and look into the issues related to it. 


\section{References}

Attaa, Aamir (2009), Ecommerce Gateway Coming to Pakistan This Month, http://propakistani.pk/2009/07/06/ecommerce-gateway-coming-to-pakistan-this-month/

Attaa, Aamir (2010) PayPal in Pakistan - Looks Possible, but it May Take Time! http://propakistani.pk/2010/04/14/paypal-in-pakistan/

Bajaj, Akhilesh, Leonard Lori N. K. (2004) The CPT Framework: Understanding the Roles of Culture, Policy and Technology in Promoting Ecommerce Readiness, Problems and Perspectives in Management, Ukraine: Business Perspectives.

Boerhanoeddin, Zuraida. (2000) E-commerce in Indonesia, ISOC Conference Proceedings, USA. Efendioglu Alev M., Yip Vincent F., Murray William L., (2004) E-Commerce in Developing Countries: Issues and Influences, IBEC Proceedings, International Business and Economy Conference, Hawaii.

Efendioglu, Alev M., Yip Vincent F., Murray William L., (2004) E-Commerce in Developing Countries: Issues and Influences, retrieved on August 15, 2009 from http://userwww.sfsu.edu/ ibec/papers/25.pdf

Greenstein, M., Vasarhelyi, M. (2002), Electronic Commerce: Security, Risk Management, and Control, 2nd ed., McGraw-Hill Irwin, Boston.

Internet World Stats (2009) Internet Usage Statistics: The Internet Big Picture, www.internetworldstats.com/stats.htm

lqbal Syed Ahsan (2008) E-Commerce: Need of Hour! Checklist for an E-commerce Store, Green and White - Coffee Sessions for the Industry, http://greenwhite.org

Khan Mehwish (2009), Setup Built to Establish First E-Commerce Gateway of Pakistan, http://propakistani.pk/2009/08/05/setup-built-to-establish-first-e-commerce-gateway-of-pakistan/

Kurnia, S. (2006) E-Commerce Adoption in Developing Countries: An Indonesian Study, San Diego International Systems Conference, 14-16 July, San Diego.

Mann Catherine L. (2000) Electronic Commerce in Developing Countries: Issues for Domestic Policy and WTO Negotiations, Services in the International Economy: Measurement, Modeling, Sectoral and Country Studies, and Issues in the World Services Negotiations, Institute for International Economics.

National Retail Federation (2004) E-Commerce the first Decade, www.shop.org

Nielsen (2008), Trends in online shopping, a global Nielsen consumer report.pdf

Petrony (2009) Internet and E-Commerce industry in Pakistan, Ecommerce Journal, www.ecommercejournal.com

Pro Pakistani (2009) E-Banking in Pakistan - An Overview, http://propakistani.pk/2009/09/11/ebanking-inpakistan/

Reynolds (2000), E-Commerce: a critical review, International Journal of Retail and Distribution Management, 28(10), MCB UP Ltd.

Sajid Mushtaq A. (2003) E-Commerce and its future in Pakistan, www.accountancy.com.pk/articles.asp?id=69

The ARY news (2009) Internet in Pakistan to hit $22 \mathrm{mln}$ by 2013 www.thearynews.com/english/newsdetail.asp?nid=32156\# 
The Economist Intelligence Unit (2006) Overview of E-Commerce in Pakistan,

http://globaltechforum.eiu.com/index.asp?layout=rich_story\&doc_id=9616\&country_id=PK\&title=Overview +of+e-commerce+in+Pakistan\&channelid=4\&categoryid=30\&country=Pakistan

Travica B. (2002) Diffusion of Electronic Commerce in Developing Countries: Case of Costa Rica, Journal of Global Information Technology Management, 5(1).

Tunyo Tariq Hussain (2008), E-Commerce: barriers to its growth in Pakistan, www.opfblog.com/1152/ecommerce-barriers-to-its-growth-in-pakistan/

Wen Joseph H., Chen Houn-Gee, Hwang Hsin-Ginn (2001) E-Commerce Web site design: strategies and models, Information Management and Computer Security, 5-12.

Wolcott P., Press L., McHenry W., Goodman S. E., Foster W. (2001) A framework for assessing the global diffusion of the Internet, Journal of the Association for Information Systems 2(6).

Zwass V. (1996) Electronic Commerce: Structure and Issues, International Journal of Electronic Commerce, 1(1). 